\title{
Comparison of Gastric Relaxation and Sensory Functions between Functional Dyspepsia and Healthy Subjects Using Novel Drinking-Ultrasonography Test
}

\author{
Tamotsu Hata $^{a}$ Mototsugu Kato ${ }^{b}$ Takahiko Kudo $^{b}$ Mutsumi Nishida ${ }^{c}$ \\ Urara Nishida $^{a}$ Aki Imai $^{\mathrm{a}}$ Takeshi Yoshida $^{a}$ Jyojyo Hirota ${ }^{a}$ Go Kamada $^{a}$ \\ Shouko Ono $^{\text {b }}$ Manabu Nakagawab Soichi Nakagawab Yuichi Shimizub \\ Hiroshi Takeda ${ }^{a}$ Masahiro Asaka ${ }^{a}$ \\ ${ }^{a}$ Department of Gastroenterology, Hokkaido University Graduate School of Medicine, and bivision of Endoscopy \\ and ${ }^{\mathrm{C} D e p a r t m e n t}$ of Clinical Laboratory, Support of Clinical Practice, Hokkaido University Hospital, Sapporo, Japan
}

\section{Key Words}

Functional gastroduodenal disorders $\cdot$ Drink test $\cdot$ Ultrasonography · Gastric accommodation - Gastric emptying $\cdot$ Visceral hypersensitivity

\section{Abstract \\ Background: Functional dyspepsia (FD) is a heterogeneous disease characterized by various upper abdominal symp- toms. The major mechanism of FD includes impaired fundic accommodation, delayed gastric emptying and visceral hy- persensitivity. We developed a novel drinking-ultrasonogra- phy test to combine a drink test with ultrasonography to as- sess gastric motility and sensory function of FD patients. Method: Subjects were 20 healthy volunteers and 26 succes- sive FD patients according to the Rome III criteria. The sub- jects ingested $200 \mathrm{ml}$ of water at 2-min intervals 4 times (to- tal $800 \mathrm{ml}$ ) through a straw. The maximum cross section of the proximal stomach was visualized before water intake, af- ter each water intake, and 5 and 10 min after the completion of drinking using extracorporeal ultrasonography. Abdomi- nal symptoms were evaluated using the visual analog scale (VAS) a total of 5 times. Results: The mean cross-sectional}

\section{KARGER}

Fax +4161306 1234

E-Mail karger@karger.ch

www.karger.com
(C) 2013 S. Karger AG, Basel

0012-2823/13/0871-0034\$38.00/0

Accessible online at:

www.karger.com/dig area of the fornix after $800 \mathrm{ml}$ of water intake was significantly lower in the FD group compared with the control group. In the FD group, marked abdominal symptoms developed immediately after initiation of water intake, and VAS score differed significantly $(p<0.01)$ between the control and FD groups at each time point. Conclusion: We developed the novel drinking-ultrasonography test which revealed abnormalities in gastric accommodation and sensation in patients with FD compared with healthy controls. This approach can be readily performed and allows the simultaneous evaluation of gastric accommodation, emptying and sensation.

Copyright $\odot 2013$ S. Karger AG, Basel

\section{Introduction}

Functional dyspepsia (FD) is a clinical condition characterized by various upper abdominal symptoms, such as postprandial fullness, early satiation and epigastric pain, or burning marked by the absence of organic, systemic or metabolic disease that would explain the symptoms. The Rome III committee proposed new diagnostic criteria for 
Table 1. Baseline characteristics of HVs and patients with FD

\begin{tabular}{lcll}
\hline & HVs $(\mathrm{n}=20)$ & FD $(\mathrm{n}=26)$ & $\begin{array}{l}\text { Statistical } \\
\text { significance }\end{array}$ \\
\hline Male/female & $10 / 10$ & $5 / 21$ & n.s. \\
Age, years & $37.0 \pm 10.3(24-53)$ & $38.6 \pm 10.3(21-59)$ & n.s. \\
BMI & $21.4 \pm 3.3$ & $20.9 \pm 5.0$ & n.s. \\
Height, cm & $166.0 \pm 8.6$ & $160.2 \pm 7.6$ & n.s. \\
Weight, $\mathrm{kg}$ & $60.4 \pm 12.2$ & $53.6 \pm 10.6$ & n.s. \\
\hline
\end{tabular}

functional gastrointestinal disorders including FD [1]. The Rome III criteria divided FD into two categories according to predominant dyspeptic symptoms: postprandial distress syndrome and epigastric pain syndrome. However, the two subtypes overlap greatly. The heterogeneity of FD symptoms depends on different pathophysiological features. The major mechanism of FD symptoms includes impaired fundic accommodation, delayed gastric emptying and visceral hypersensitivity, as well as other complicating factors $[2,3]$. It seems likely that an understanding of pathophysiology in different types of FD patients is required for different management approaches.

Tests of gastric motility and sensory function are available in clinical practice. Gastric barostat is regarded as the gold standard for the measurement of gastric accommodation $[4,5]$. However, it is not widely used because the procedure is extremely invasive. Imaging methods such as single photon emission computer tomography, magnetic resonance imaging or scintigraphy have also been occasionally reported [6-9]. These tests cannot be used extensively because of radiation exposure and long examination time. On the other hand, ultrasonography, which is safe, noninvasive and inexpensive, allows the direct observation of gastric movements [10-12]. In addition, a drink test has recently been developed for the evaluation of sensory function [13-15]. We combined a similar drink test of our own design with ultrasonography to assess the gastric motility and sensory function of FD patients in terms of a pathophysiological classification and compared the gastric motor and sensory functions of healthy subjects and FD patients [16].

\section{Subjects and Methods}

\section{Subjects}

Twenty healthy volunteers (HVs) and 26 successive subjects diagnosed with FD according to the Rome III criteria at Hokkaido University Hospital between August 2006 and August 2007 were enrolled in this study. FD patients had had one or more of the following symptoms in the preceding 3 months: postprandial fullness, early satiation, epigastric pain or burning. All subjects underwent upper gastrointestinal endoscopy and abdominal ultrasonography to exclude organic abdominal disease. This study was approved by the Ethics Committee of Hokkaido University Hospital and written informed consent was obtained from all subjects.

\section{Basic Procedure}

A drinking-ultrasonography test was performed after subjects had fasted for at least $6 \mathrm{~h}$. Subjects were supine and ingested water through a straw that was placed at facial height so that they raised themselves minimally. Commercially available water in PET bottles (Alkali Ion Water ${ }^{\circledR}$; Kirin, Tokyo, Japan) and graduated plastic cups were used. During the drinking period, the subjects ingested $200 \mathrm{ml}$ of water at 2 -min intervals 4 times (total $800 \mathrm{ml}$ ). When they felt unable to ingest more, the test was discontinued. Examination of the emptying period was conducted 5 and $10 \mathrm{~min}$ after the completion of drinking $800 \mathrm{ml}$ (or discontinuation), at which point the test was concluded (fig. 1).

\section{Evaluation of the Gastric Cross-Sectional Area}

All ultrasonographic examinations were performed using an Aplio $^{\text {TM }}$ XV (Toshiba, Tokyo, Japan) and a 3.5-MHz convex-type probe (375BT) by one ultrasonography technician with more than 20 years of experience. The cross section of the proximal stomach was visualized by extracorporeal ultrasonography via the 10th intercostal space using the spleen as an echo window. The maximum cross section of the proximal stomach was visualized before water intake, after each water intake at 2-min intervals, and 5 and $10 \mathrm{~min}$ after the completion of the drinking test. After the image was frozen the mucosal surface of the gastric lumen was traced using the ultrasonography system and the cross-sectional area was calculated. Static and animated images were stored on hard disk.

\section{Evaluation of Symptoms}

During the drinking period, abdominal symptoms were evaluated using the visual analog scale (VAS) a total of 5 times, as well as before the test and immediately after each ingestion of water. Abdominal symptoms before the test were used as the baseline. Subjects were asked about difficulty in drinking due to symptoms such as abdominal fullness and epigastric pain. During the test they filled out a questionnaire by themselves using a numerical scale from 0 (no difficulty) to 10 (most difficult). 



Fig. 1. The cross section of the proximal stomach was visualized by extracorporeal ultrasonography via the 10th intercostal space using the spleen as an echo window. The maximum cross section of the proximal stomach was visualized before water intake and after each $200 \mathrm{ml}$ intake up to $800 \mathrm{ml}$.

Statistical Analysis

All values are expressed as the mean \pm SD. Differences between the two groups were analyzed by Student's t test and $\mathrm{p}$ values of less than 0.05 were considered to indicate statistical significant. All data were statistically analyzed using SPSS software (version 11.0 for Microsoft Windows).

\section{Results}

\section{Baseline Characteristics}

The healthy control group consisted of 20 subjects (10 males and 10 females) with a mean age of 37.0 (24-53) years and a mean BMI of 21.4. The FD group consisted of 26 patients ( 5 males and 21 females) with a mean age of $38.6(21-59)$ years and a mean BMI of 20.9 (table 1).

\section{Gastric Accommodation}

The mean cross-sectional area of the fornix after 800 $\mathrm{ml}$ of water intake was significantly lower in the FD group $\left(75.2 \pm 19.0 \mathrm{~cm}^{2}\right)$ compared with the control group $(98.5$ $\pm 23.7 \mathrm{~cm}^{2}$; fig. 2).

\section{Gastric Emptying}

The percentages of the cross-sectional area of the fornix after 5 and 10 min were $81.7 \pm 14.8 \%$ and $69.6 \pm 15.7 \%$, respectively, in the control group and $86.0 \pm 25.2 \%$ and $77.5 \pm 28.4 \%$, respectively, in the FD group. Although no significant differences were observed $(p=0.272)$ between the two groups, the mean value of the cross-sectional area of the fornix in the FD group was higher than that in the control group, suggesting delayed emptying in FD (fig. 3). 


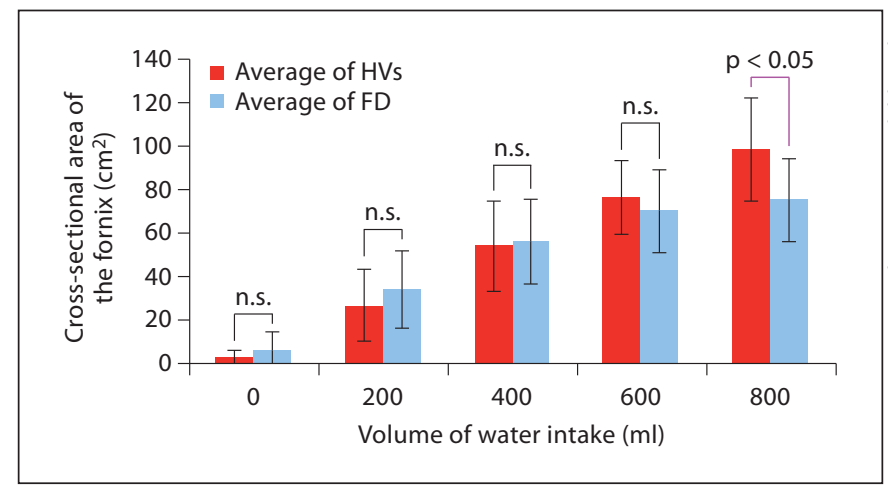

Fig. 2. The cross-sectional area of the fornix (gastric accommodation) during the drinking-ultrasonography test. Impairment of gastric accommodation was significant in FD patients on $800 \mathrm{ml}$ of water intake.

\section{Gastric Sensation}

In the FD group, marked symptoms such as abdominal fullness and epigastric pain developed immediately after the initiation of water intake, and the VAS score tended to be high compared with the HVs. The VAS score differed significantly $(\mathrm{p}<0.01)$ between the control and FD groups at each time point (after $200 \mathrm{ml}$ of water intake, $0.5 \pm 1.5$ vs. $2.8 \pm 3.5$; after $400 \mathrm{ml}$ of water intake, $1.4 \pm 1.9$ vs. $4.2 \pm 3.3$; after $600 \mathrm{ml}$ of water intake, 2.7 \pm 2.3 vs. $6.2 \pm 3.2$; after $800 \mathrm{ml}$ of water intake, $4.2 \pm$ 2.8 vs. $7.0 \pm 3.3$, respectively), suggesting hyperesthesia in the FD group (fig. 4).

\section{Discussion}

We developed the drinking-ultrasonography test and evaluated the pathological condition of patients with FD in comparison with HVs. In this drinking-ultrasonography test a drink load is given at equal intervals, the crosssectional area of the fornix is measured and symptoms are verbally assessed at each interval. This approach allows the simultaneous evaluation of gastric relaxation, sensory function and gastric emptying. It seems that the greatest benefit of the drinking-ultrasonography test is its noninvasive nature, ease of use, tolerability and short duration (under $20 \mathrm{~min}$ ) for patients. Recently, minimally invasive tests of gastric motility and sensory function have been reported, such as ultrasonography, 13C-octanoic acid urea breath test and drink test. These tests are able to evaluate gastric relaxation, gastric emptying, gastroduodenal reflux or visceral hypersensitivity. Howev-

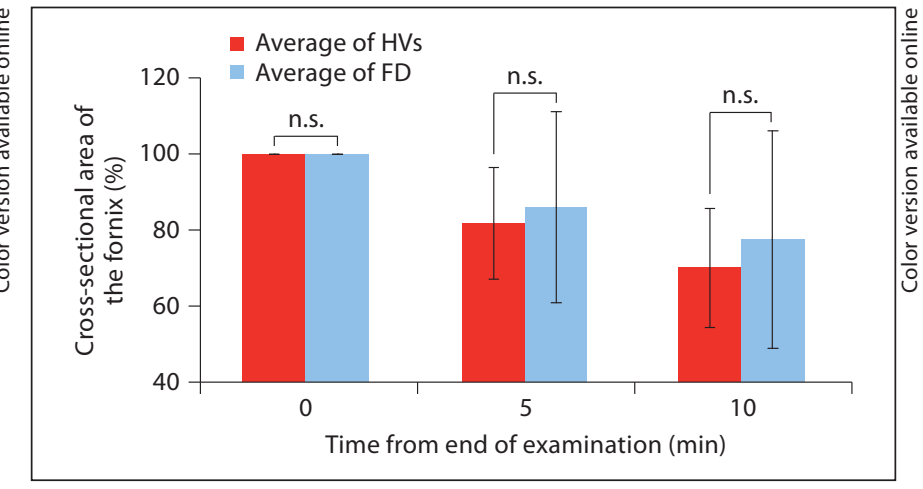

Fig. 3. Cross-sectional area of the fornix after water intake. No significant difference was recognized between the groups.

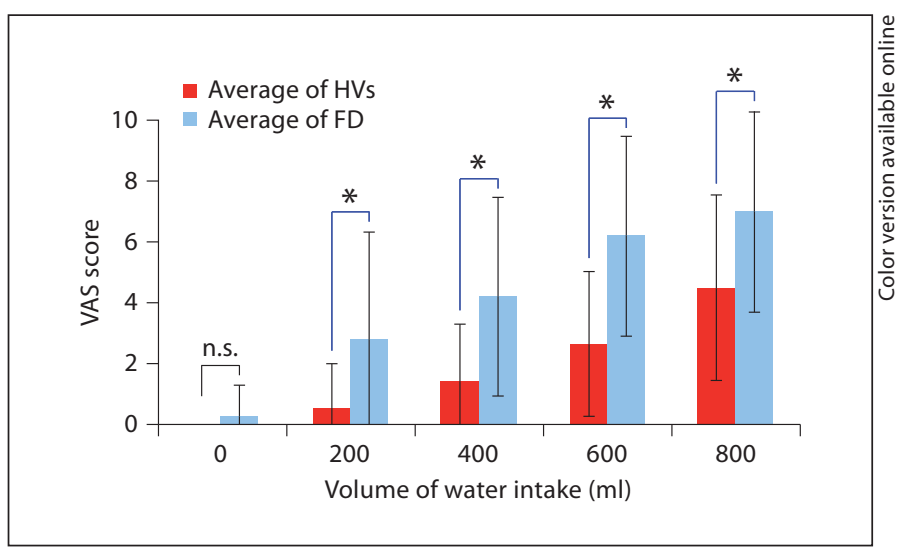

Fig. 4. VAS during the drinking-ultrasonography test. FD groups tended to complain of upper-gastrointestinal symptoms from an early stage of the examination. ${ }^{*} \mathrm{p}<0.01$.

er, these minimally invasive tests do not detect simultaneously both gastric motor disorder and sensory disorder. The drinking-ultrasonography test does not require radiation, expensive chemical substances or unusual equipment. In terms of money and time-saving, this novel test is useful for routine examination of dyspeptic patients.

To develop the drinking-ultrasonography test, we examined adequate interval time, tidal volume and total volume of water intake. Initially, $100 \mathrm{ml}$ of water intake at 1-min intervals was considered based on the study by Boeckxstaens et al. [13]. However, at these intervals the time available for ultrasonography was very short and in- 
quiry into symptoms was inadequate. Then we tried and evaluated $100-\mathrm{ml}$ intakes at $5-\mathrm{min}$ intervals and $200-\mathrm{ml}$ intakes at 2-min intervals. The former proved to be timeconsuming and ingested water flowed into the duodenum and deeper areas early during the test, causing high data variance. The intake of $200 \mathrm{ml}$ of water at 2-min intervals did not produce this phenomenon or high data variance and was considered optimal. However, to avoid maximum satiety of the subjects, the determination of the upper limit of water intake was necessary. Since the mean cross-sectional area of the fornix showed significant differences after about $800 \mathrm{ml}$ of intake between HVs and FD patients, the intake of $800 \mathrm{ml}$ of water was considered appropriate. With regard to the test meal, another way to assess the postprandial gastric function is by evaluation using a solid meal. The results of liquid gastric emptying are not completely consistent with those of solid gastric emptying. Liquid emptying is usually faster than solids, although a recent study has shown a better association of delayed gastric emptying of solids and liquids with symptoms of postprandial fullness, nausea and vomiting [17]. Previous studies have shown that acid secretion due to fat intake affects gastric movement, causing hyperesthesia of visceral organs $[17,18]$. Another report has also shown that there is a slowing of liquid emptying with increasing nutrient and caloric content of the meal [19]. Considering this, we used loading of zero-calorie mineral water in this study. Further studies involving loading of calorie-containing liquids may be necessary and interesting.

In this study, the VAS score during water intake significantly differed between the HVs and the FD group. The reported incidence of impaired gastric accommodation in patients with FD is about $40-50 \%$ [20], and several studies have also shown gastric impairment in patients with FD compared with healthy subjects $[6,9]$. Symptoms due to relaxation failure have been suggested to be caused by excessive excitation of fundic stretch receptors [21] or contents moved to the antrum early due to distension failure [22]. Delayed gastric emptying has long been considered the main pathology of FD and has been extensively studied. Recent studies have shown that the incidence of delayed gastric emptying is about 25\% [23, 24 , and many studies have suggested no association between delayed gastric emptying and specific symptoms. In the present study, slightly delayed gastric emptying was observed in the FD group, but there were no significant differences between the two groups.

The pathophysiological mechanisms of FD include motility disorders, perception disorders, acid hypersen- sitivity, psychological factors, Helicobacter pylori infection, duodenal dysfunction and abnormalities within the brain-gut axis. In this study, we did not check the $H$. $p y$ lori status of enrolled subjects. The reported prevalence of $H$. pylori infection in FD patients varies from 39 to $87 \%$ [25]. Although H.pylori infection is thought to be a cause of FD symptoms, no association between $H$. pylori positivity and symptom pattern, gastric emptying rate, gastric accommodation or sensitivity to distension in FD patients has been found [16]. Also, consistent results on the response of FD symptoms to $H$. pylori eradication therapy have not been obtained [26, 27]. Further study is necessary and will be interesting to clarify the relationship between the pathophysiological classification using this novel test and the strategy of FD treatment.

\section{Conclusion}

The drinking-ultrasonography test revealed abnormalities in gastric accommodation and sensation in patients with FD compared with HVs. This test can be readily performed and allows the simultaneous evaluation of gastric relaxation, emptying and sensation.

\section{Disclosure Statement}

The authors declare that no financial or other conflicts of interest exist in relation to the content of this article.

References

- Talley NJ, Camilleri M, Holtmann G, Hu P, Malagelada JR, Stanghellini V: Functional gastroduodenal disorders. Gastroenterology. 2006;130:1466-1479.

- Tack J, Piessevaux H, Coulie B, Caenepeel P, Janssens J: Role of impaired gastric accommodation to a meal in functional dyspepsia. Gastroenterology 1998;115:1346-1352.

3 Tack J, Lee KJ: Pathophysiology and treatment of functional dyspepsia. J Clin Gastroenterol 2005;39:S211-S216.

4 Azpiroz F, Malagelada JR: Physiological variations in canine gastric tone measured by an electronic barostat. Am J Physiol 1985; 248:G229-G237.

5 Tack J, Caenepeel P, Fischler B, Piessevaux H, Janssens J: Symptoms associated with hypersensitivity to gastric distention in functional dyspepsia. Gastroenterology 2001;121:526535 . 
6 Piessevaux H, Tack J, Walrand S, Pauwels S, Geubel A: Intragastric distribution of a standardized meal in health and functional dyspepsia: correlation with specific symptoms. Neurogastroenterol Motil 2003;15:447-455.

7 van den Elzen BD, Bennink RJ, Wieringa RE, Tytgat GN, Boeckxstaens GE: Fundic accommodation assessed by SPECT scanning: comparison with the gastric barostat. Gut 2003;52:1548-1554.

$>8$ de Zwart IM, Mearadji B, Lamb HJ, Eilers PH, Masclee AA, de Roos A, Kunz P: Gastric motility: comparison of assessment with real-time MR imaging or barostat measurement initial experience. Radiology 2002;224: 592-597.

$>9$ Fruehauf H, Goetze O, Steingoetter A, Kwiatek M, Boesiger P, Thumshirn M, Schwizer $\mathrm{W}$, Fried M: Intersubject and intrasubject variability of gastric volumes in response to isocaloric liquid meals in functional dyspepsia and health. Neurogastroenterol Motil 2007;19:553-561.

$>10$ Schwizer W, Steingötter A, Fox M, Zur T, Thumshirn M, Bösiger P, Fried M: Noninvasive measurement of gastric accommodation in humans. Gut 2002;51:i59-i62.

-11 Kusunoki H, Haruma K, Hata J, Tani H, Okamoto E, Sumii K, Kajiyama G: Real-time ultrasonographic assessment of antroduodenal motility after ingestion of solid and liquid meals by patients with functional dyspepsia. J Gastroenterol Hepatol 2000;15: 1022-1027.

$>12$ Gilja OH, Lunding J, Hausken T, Gregersen $\mathrm{H}$ : Gastric accommodation assessed by ultrasonography. World J Gastroenterol 2006; $12: 2825-2829$.
13 Boeckxstaens GE, Hirsch DP, Kuiken SD, Heisterkamp SH, Tytgat GN: The proximal stomach and postprandial symptoms in functional dyspeptics. Am J Gastroenterol 2002;97:40-48.

14 Jones MP, Hoffman S, Shah D, Patel K, Ebert CC: The water load test: observations from healthy controls and patients with functional dyspepsia. Am J Physiol Gastrointest Liver Physiol 2003;284:G896-G904.

15 Gonenne J, Castillo EJ, Camilleri M, Burton D, Thomforde GM, Baxter KL, Zinsmeister AR: Does the nutrient drink test accurately predict postprandial gastric volume in health and community dyspepsia? Neurogastroenterol Motil 2005; 17:44-50.

16 Kato M, Nishida U, Nishida M, Hata T, Asaka R, Haneda M, Yamamoto K, Imai A, Yoshida T, Ono S, Shimizu Y, Asaka M: Pathophysiological classification of functional dyspepsia using a novel drinking-ultrasonography test. Digestion 2010;82:162-166.

17 Sarnelli G, Caenepeel P, Geypens B, Janssens J, Tack J: Symptoms associated with impaired gastric emptying of solids and liquids in functional dyspepsia. Am J Gastroenterol 2003;98:783-788.

18 Drossman DA: The functional gastrointestinal disorders and the Rome III process. Gastorenterology 2006;130:1377-1390.

19 Collins PJ, Houghton LA, Read NW, Horowitz M, Chatterton BE, Heddle R, Dent J: Role of the proximal and distal stomach in mixed solid and liquid meal emptying. Gut 1991;32:615-619.

20 Lee KJ, Vos R, Janssens J, Tack J: Influence of duodenal acidification on the sensorimotor function of the proximal stomach in humans. Am J Physiol Gastrointest Liver Physiol 2004;286:G278-G284.
21 Feinle C, Rades T, Otto B, Fried M: Fat digestion modulates gastrointestinal sensations induced by gastric distention and duodenal lipid in humans. Gastroenterology 2001;120: 1100-1107.16

22 Caldarella MP, Azpiroz F, Malagelada JR: Antrofundic dysfunctions in functional dyspepsia. Gastroenterology 2003;124:1220 1229.

23 Lee KJ, Vos R, Janssens J, Tack J: Differences in the sensorimotor response to distension between the proximal and distal stomach in humans. Gut 2004;53:938-943.

24 Talley NJ, Verlinden M, Jones M: Can symptoms discriminate among those with delayed or normal gastric emptying in dysmotilitylike dyspepsia? Am J Gastroenterol 2001;96: 1422-1428.

25 Lambert JR: The role of Helicobacter pylori in nonulcer dyspepsia: a debate - for. Gastroenterol Clin North Am 1993;22:141-151.

26 Blum AL, Talley NJ, O’Moráin C, van Zanten SV, Labenz J, Stolte M, Louw JA, Stubberöd A, Theodórs A, Sundin M, Bolling-Sternevald E, Junghard O: Lack of effect of treating Helicobacter pylori infection in patients with nonulcer dyspepsia. Omeprazole plus Clarithromycin and Amoxicillin Effect One Year after Treatment (OCAY) Study Group. N Engl J Med 1998;339:1875-1881.

27 McColl K, Murray L, El-Omar E, Dickson A, El-Nujumi A, Wirz A, Kelman A, Penny C, Knill-Jones R, Hilditch T: Symptomatic benefit from eradicating Helicobacter pylori infection in patients with nonulcer dyspepsia. N Engl J Med 1998;339:1869-1874. 